\title{
Comparable Cellular Immune Responses in Patients with and without Antiretroviral Treatment after Immunization with HIV-1 P24, P17 and Tat Consensus Peptides (Vacc-5q)
}

Anne-Marte B Kran ${ }^{1,3 *}$, Andreas Lind ${ }^{2,3}$, Maja M Sommerfelt ${ }^{4}$, Ingebjørg Baksaas ${ }^{5}$, Birger Sørensen ${ }^{4}$ and Dag Kvale ${ }^{2,3}$

${ }^{1}$ Department of Microbiology, Oslo University Hospital, Oslo, Norway

${ }^{2}$ Department of Infectious Diseases, Oslo University Hospital, Norway

IInstitute of Clinical Medicine, University of Oslo, Norway

${ }^{4}$ Bionor Pharma ASA, Oslo, Norway

${ }^{5}$ Mericon AS, Skien, Norway

\begin{abstract}
Objectives: Therapeutic vaccination in chronic HIV-infection aims to attenuate disease progression by promoting new HIV-specific T cell-clones. Most clinical trials with therapeutic vaccines are conducted on patients receiving antiretroviral therapy (ART). However, studies of vaccination in untreated individuals are limited. We present the first data from a phase I/II clinical trial with a peptide-based therapeutic vaccine (Vacc-5q) consisting of five short, modified consensus peptides from p17, p24, and Tat. In addition to evaluating safety and immunogenicity of Vacc-5q, we compared responses induced in patients on effective ART with those of ART-naïve patients.
\end{abstract}

Methods: HIV-infected patients stable on ART $(n=10)$ and treatment naive patients $(n=10)$ received 11 intradermal injections of Vacc-5q over 26 weeks, using GM-CSF as an adjuvant. Immunogenicity was assessed both in vivo by delayed type hypersensitivity (DTH) skin tests, and in vitro by T cell activation assays. Persistence of immune responses was retested after 3.5 years.

Results: Vacc-5q was found to be immunogenic. Specific $T$ cell-responses both in vivo and in vitro increased significantly from baseline to week $4(p<0.01)$, and were still present after 3.5 years. No significant differences were observed between ART treated and ART naïve patients at any time point.

Conclusion: Vacc-5q induced potent HIV associated cellular immune responses both in ART treated and in treatment-naïve viremic patients. These responses were comparably strong in both study arms and still present after 3.5 years, indicating that suppression of plasma viral load by ART might not be essential for optimal immunization.

Keywords: HIV-1; Therapeutic vaccines; Delayed type hypersensitivity; $\mathrm{T}$ cell-response; Immunization; Peptide; $\mathrm{T}$ cell activation

\section{Introduction}

Ineffective immune control of chronic human immunodeficiency virus type-1 (HIV) infection leads to a progressive loss of immune functions and AIDS if not effectively treated $[1,2]$. Therapeutic vaccines aim to improve HIV-specific immunity and control of viral replication with theoretical potentials to attenuate the disease progression, postpone combination antiretroviral treatment (ART), further reduce the residual HIV replication under an ART regimen, reduce viral reservoirs, or be part of treatment strategies to eradicate the virus [3].

Several therapeutic vaccine candidates have demonstrated induction or reimbursement of HIV-specific immune responses [4-10]. In these trials, patients have generally been immunized while receiving ART, because suppressed viral replication should theoretically better protect activated vaccine-induced $\mathrm{T}$ cells from HIV entry, and provide optimal conditions for priming of new $\mathrm{T}$ cell-responses. Roll-out of approved therapeutic vaccines in the future face practical and economic challenges if their use requires early introduction of ART, particularly in resource-poor settings. The question whether ART is required for effective therapeutic vaccine has previously been explored in a few clinical studies [11-16]. We here report data from an early phase I/II clinical trial of a therapeutic vaccine candidate (Vacc-5q). In addition to a study arm with patients on effective ART, a parallel ART-free study arm with comparable $\mathrm{CD} 4+\mathrm{T}$ cell counts was included, primarily for safety reasons of immunization during chronic antigenemia. This study design also enabled us to test whether ART was a prerequisite for immunisation at an early phase. Vacc-5q consists of altogether five peptides corresponding to Gag (p24 and p17) and Tat consensus sequences; one of the two p24 peptides has been included in another therapeutic vaccine candidate that we have tested previously (Vacc- $4 \mathrm{x}$ ) to allow for the potential to compare immunogenicity $[4,10,17-20]$. The objectives in this trial were to evaluate safety and immunogenicity of Vacc-5q. We hypothesized that ART was not prerequisited for effective immunization with a peptide-based vaccine, and wanted to explore the significance of ART on immunization by comparing induced, vaccine-specific immune responses in patients with and without treatment. The study design comparing these two patients groups was motivated by the possibility for simplified roll-out of therapeutic vaccines in resource-limited populations without access to ART.

*Corresponding author: Anne-Marte Bakken Kran, Ullevål Department of Microbiology, Oslo University Hospital, Ullevål, N-0407 Oslo, Norway, Tel: +47 2211 85 04/ +47 221188 45; Fax: +47 221188 42; E-mail: a.m.b.kran@medisin.uio.no

Received February 14, 2014; Accepted March 29, 2014; Published April 10, 2014

Citation: Kran AMB, Lind A, Sommerfelt MM, Baksaas I, Sørensen B, et al. (2014) Comparable Cellular Immune Responses in Patients with and without Antiretroviral Treatment after Immunization with HIV-1 P24, P17 and Tat Consensus Peptides (Vacc-5q). J AIDS Clin Res 5: 296. doi:10.4172/2155-6113.1000296

Copyright: ( $2014 \mathrm{Kran}$ AMB, et al. This is an open-access article distributed under the terms of the Creative Commons Attribution License, which permits unrestricted use, distribution, and reproduction in any medium, provided the original author and source are credited. 
Citation: Kran AMB, Lind A, Sommerfelt MM, Baksaas I, Sørensen B, et al. (2014) Comparable Cellular Immune Responses in Patients with and without Antiretroviral Treatment after Immunization with HIV-1 P24, P17 and Tat Consensus Peptides (Vacc-5q). J AIDS Clin Res 5: 296. doi:10.4172/2155-6113.1000296

Page 2 of 8

\section{Methods}

\section{Vacc-5q composition and manufacturing}

Vacc-5q is composed of five water-soluble peptides (17-22 amino acids in length) synthesized by Polypeptides GmbH, Germany, vials were filled and labelled by Isopharma. The individual peptides are based on consensus HIV-1 sequences within p17, p24, and Tat, respectively. The native sequences from HXB2 reference strain (Table 3), represent the regions used as a basis for peptide design. The particular Vacc- $5 \mathrm{q}$ peptides are targeted because p 24 is a highly antigenic viral protein and is an important target of immune responses to HIV-1. Tat is expressed early in infection, is a potent activator of virus transcription, and exerts a wide range of pathogenic effects both in infected and uninfected cells following uptake. The structural protein $\mathrm{p} 17$ is involved in transporting the newly reverse transcribed viral genome to the nucleus for integration into the host genome. Targeting p17 may therefore reduce viral spread in an infected individual. Each of the Vacc-5q consensus peptides in addition contained some near-native $T$ cell epitopes modified by single amino acid substitutions to facilitate HLA binding and presentation, and thereby improve cellular immune responses to their native peptide counterparts. All vaccine peptides contain HLA-A2 restricted motifs, but the vaccine was not designed to correspond to the individual HLA tissue types of the subjects enrolled.

\section{Study protocol and inclusion criteria}

This open, prospective randomized phase I/II clinical study included 20 asymptomatic patients with chronic HIV-infection lasting more than 1 year at enrolment, aged over 18 years, and in generally good health. Two study arms were defined: (i) ART-naïve patients with CD4+ lymphocyte count $>500 / \mu 1$ and CD4+ lymphocyte count reduction less than $150 / \mu$ l the last year prior to study inclusion (nonART group); and (ii) patients on ART who had been clinically stable for 6 months including HIV RNA $<400$ copies $/ \mathrm{ml}$, and nadir and current CD4+ lymphocyte counts above $75 / \mu \mathrm{l}$ and $200 / \mu \mathrm{l}$ respectively (ART group). Exclusion criteria were concurrent malignant disease, immunosuppressive therapy, pregnancy or lactation. Primary objectives were safety and tolerability of Vacc-5q, and secondary objectives were to compare immune responses in vivo by delayed-type hypersensitivity testing (DTH) and in vitro T cell responses in both study groups as well as explore the impact of concurrent ART.
The immunization period over the first 26 weeks consisted of intradermal injections, where Vacc- $5 \mathrm{q}$ was given as a $100 \mu \mathrm{l}$ solution with $0.3 \mathrm{mg}$ of each of the five Vacc-5q peptides dissolved in sterile water. Fifteen minutes prior to injection with Vacc-5q, $60 \mu \mathrm{g}$ recombinant human GM-CSF (Sargramostim (Leukin ${ }^{\bullet}$ ), Berlex, Seattle, USA) was injected intradermally as a local adjuvant at the vaccine injection site. A total of 11 immunizations were given in the induction phase at weeks 1 (3 times: day 1.3.5), 2 ( 2 times: day 1,3), 3, 4, and 6, and as booster injections at weeks 24,25 , and 26 . Two treatment interruptions were included in the ART group, mainly to rule out viremia-associated adverse events, but also as a possible boosting of the induced HIV specific immune responses. The protocol is outlined in Figure 1.

Three years after the end-of-study, patients were re-invited to participate in a follow-up study, which included a clinical examination, blood samples and a single DTH skin test. Both the core study and the follow-up were approved by the Norwegian Medicines Control Authority and the South-Eastern Regional Committee for Medical and Health Research Ethics with written informed consents from all participants. The study was conducted in accordance with the Declaration of Helsinki of 1964, (revised version of Edinburgh 2000) and the Notes for Guidance on Good Clinical Practice (CPMP/ICH/135/95), dated July 17 1996, and applicable regulatory requirements.

\section{Clinical monitoring}

Patients were monitored at all visits for adverse events, Karnofsky performance status, vital signs (heart rate, blood pressure, and weight) and general laboratory tests. Adverse events were registered and scored according to the MedDRA System Organ. All safety laboratory parameters were listed and evaluated with respect to their normal ranges according to NCI-CTC version 3.0. The CD4+ and CD8+ T lymphocyte counts were measured using the TriTEST reagent kit (Becton Dickinson (BD)). HIV RNA was monitored by the COBAS Amplicor HIV-1 monitor test (Roche) with a detection limit of 50 copies $/ \mathrm{ml}$. All blood samples were collected prior to immunisation. The indications for starting or restarting ART followed the European guidelines at the time of study, including a CD4 count $<350 / \mu$ l.

\section{Immune response monitoring in vivo by DTH}

Delayed type hypersensitivity (DTH) skin tests were done at baseline (week 1; day 1) and repeated at weeks 3, 6, 24, 28, 40. Solutions

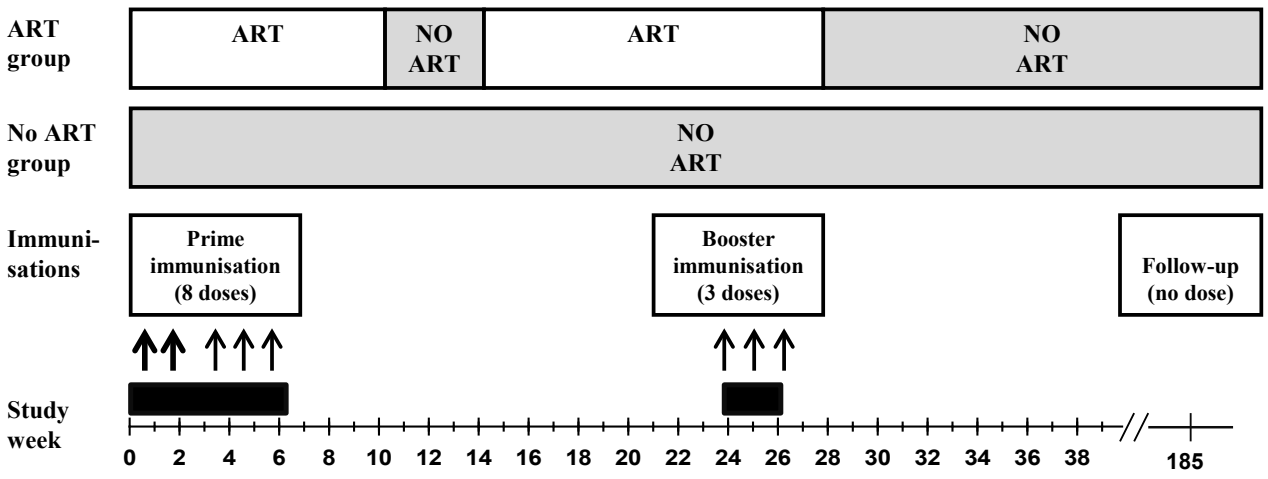

Figure 1: Study outline.

Antiretroviral treatment (ART) throughout the study is indicated at the top for both study arms. For the ART group, the schedule included two treatment interruptions of 4 and 12 weeks, respectively, separated by 14 weeks on ART. Periods with treatment are shown in white boxes marked 'ART', and periods without treatment are in shaded boxes marked 'NO ART'. Immunization periods are indicated with arrows.

Immunizations were given in two blocks at 11 different time-points: The prime immunization at weeks 1 ( 3 injections), 2 ( 2 injections), 3 , 4 , and 6 , and booster immunizations at weeks 24,25 , and 26. 
Citation: Kran AMB, Lind A, Sommerfelt MM, Baksaas I, Sørensen B, et al. (2014) Comparable Cellular Immune Responses in Patients with and without Antiretroviral Treatment after Immunization with HIV-1 P24, P17 and Tat Consensus Peptides (Vacc-5q). J AIDS Clin Res 5: 296. doi:10.4172/2155-6113.1000296

Page 3 of 8

of $100 \mu$ l water containing a mixture of each of the five Vacc-5q peptides were injected intradermally without previous injection of GM-CSF. All subjects received $0.1 \mathrm{mg}$ (DTH high) on one forearm, and $0.01 \mathrm{mg}$ (DTH low) on the other. After 48 hours, the perpendicular diameters of palpable skin infiltrates were registered, and the approximate circular areas were calculated accordingly. Induration areas above $10 \mathrm{~cm}^{2}$ were considered positive, based on historic controls [4,17]. At follow-up week 185, the volunteers were tested with DTH high.

\section{Assays for monitoring antigen-specific $\mathrm{T}$ cell responses in vitro}

Sample preparation and antigen stimulation: Peripheral-blood mononuclear cells (PBMC) were prepared using Cell Preparation Tubes $\left(\mathrm{CPT}^{\mathrm{TM}}, \mathrm{BD}\right)$. Except for week 185, freshly drawn PBMC were cultured in serum-free culture medium (Gibco AIM V, Invitrogen, cat. no. 12055-091) with 0.1\% human albumin in all assays, where parallel stimulations were done with a mix of Vacc-5q antigen peptides (Isopharma Amersham Health) $(2.5 \mu \mathrm{g} / \mathrm{ml} /$ peptide) and mixes of recombinant p17, p24 and Tat proteins (National Institute for Biological Standards and Control, UK) $(2 \mu \mathrm{g} / \mathrm{ml} /$ peptide $)$. At week 185, PBMC were first cryopreserved as earlier described [21] and later thawed en bloc, washed and reconstituted in serum-free culture medium overnight. PBMC were then subjected to peptide antigens as described above. All assays included duplicate unstimulated negative control cultures and positive control cultures stimulated with Staphylococcal enterotoxin B at $0.5 \mu \mathrm{g} / \mathrm{ml}$ (Sigma-Aldrich, cat. no 11100-45-1).

Assay for T-cell activation and proliferation: After antigen stimulation, $\mathrm{PBMC}$ were cultured at $37{ }^{\circ} \mathrm{C}$ in $5 \% \mathrm{CO}_{2}$ for 5 days, and then harvested, stained and prepared for flow cytometric analysis. Specific T cell-proliferation was concurrently measured at weeks 0,10 , and at completion of the study week 40 as well as at follow-up week 185. PBMC were pulse-labelled with carboxyfluorescein succinimidyl ester (CFSE, Invitrogen Molecular Probes, cat. no. C34554) prior to antigen stimulation, as detailed earlier [4]. For more frequent and less laborious and cytotoxic monitoring of antigen-specific activation, changes in CD25-expression relative to unstimulated cells within the CD4+ and CD8+ $\mathrm{T}$ cell subsets were estimated at all visits, in PBMC not labelled with CFSE [22]. CD25 is an activation marker that peaks after several days of stimulation, and is an adequate marker of specific T cell-responses correlating with CFSE-based assays [23,24]. Finally, detection of antigen-induced intracellular $\mathrm{T}$ cell cytokine responses of IFN- $\gamma$ and IL-2 after $20 \mathrm{~h}$ in PBMC was performed at baseline and weeks 10 and 40, as described elsewhere [25].

Staining was done with the following fluorescence-labelled mAbs: CD3 PE (eBioscience (eB), cat. no. 12-0037), CD4 FITC (eB, cat. no. 11-0048), CD8 PerCP (BD, cat. no. 345774) and CD25 APC (eB, cat. no. 17-0259).

Flow cytometry and data processing: Flow cytometry data were obtained with a BD FACS Calibur flow cytometer for all samples from weeks $0-40$, where fluorochrome-labelled IgG1, IgG2a, and $\operatorname{IgG} 2 \mathrm{~b}$ isotype control antibodies (BD) were used to calibrate all four flow channels. A BD FACS Canto II with BD Diva software V5 was used to obtain the flow data from week 185. All flow cytometry data were analysed with WinList V7 (Verity Software House), and only gates containing $\mathrm{CD} 3+\mathrm{T}$ lymphocytes and lymphoblast were evaluated. Cells with reduced CFSE fluorescence was denoted CFSEdim as described elsewhere [23]. Antigen specific $\mathrm{T}$ cell proliferation was defined as fractions of CFSEdim from antigen stimulated $\mathrm{T}$ cells above corresponding CFSEdim -fractions in control cultures as previously described [4]. Overall proliferative response rate was defined as the fraction of patients with improved proliferative response relative to baseline at a time-point. Antigen specific CD4+ and CD8+ T cell activation was defined as fractions of $\mathrm{CD} 25+$ from antigen stimulated $\mathrm{T}$ cells above unstimulated control cells.

\section{Statistical analysis}

All data are presented as median values (interquartile range). Nonparametrical statistics was used throughout the study, Mann-Whitney U test for comparing independent groups, Spearman rank for correlation analysis and Wilcoxon signed-rank test for analysing dependent variables. A bivariate immune response variable was considered positive if higher than baseline for the given individual, and Fisher exact test were used for proportional group comparisons. p-values $<0.05$ were considered statistically significant. Two-tailed test were generally used unless paired tests had indicated a uni-directional change. Statistical analyses were done using Statistica software (Statsoft Inc.).

\section{Results}

\section{Patients and clinical data}

A total of 20 patients (19 males, 1 female) were included over a

\begin{tabular}{|c|c|c|c|}
\hline & Non-ART $(n=10)$ & differences* $p$ & ART $(n=10)$ \\
\hline Age (years) & $46(38-55)$ & n.s. & $46(42-52)$ \\
\hline Males : females & $9: 1$ & n.s & $10: 0$ \\
\hline Estimated time from seroconversion (months) & $30(22-40)$ & 0.005 & $117(114-136)$ \\
\hline Time HIV seropositive (months) & $31(15-44)$ & 0.02 & $102(46-120)$ \\
\hline Nadir CD4+ T lymphocyte count (cells/ $\mu \mathrm{l})$ & n.a. & & $190(170-230)$ \\
\hline Time from nadir (months) & n.a. & & $56(22-83)$ \\
\hline Time on ART (months) & n.a. & & $55(27-81)$ \\
\hline $\mathrm{CD}^{+} \mathrm{T}$ cells $($ cells $/ \mu \mathrm{l})$ & $710(550-840)$ & n.s. & $535(390-690)$ \\
\hline CD8 ${ }^{+} \mathrm{T}$ cells $($ cells $/ \mu \mathrm{l})$ & $1313(1195-2115)$ & 0.004 & $880(705-1140)$ \\
\hline HIV RNA (copies/ml) & $25000(5400-64500)$ & $<0.001$ & $<50(<50-<50)$ \\
\hline$\beta_{2}$-microglobulin (\%) & $1.7(1.6-2.7)$ & 0.012 & $1.3(1.1-1.5)$ \\
\hline $\lg G$ & $15.4(12.1-22.1)$ & 0.01 & $11.0(8.9-12.4)$ \\
\hline CD38 ${ }^{+}$fraction of CD8+ $\mathrm{T}$ cells $(\%)$ & $65(61-74)$ & 0.001 & $35(28-41)$ \\
\hline $\mathrm{CD}^{2} 8^{+}$fraction of CD8+ $\mathrm{T}$ cells $(\%)$ & $24(15-26)$ & 0.045 & $42(29-56)$ \\
\hline
\end{tabular}

* Mann-Whitney U Test 
Citation: Kran AMB, Lind A, Sommerfelt MM, Baksaas I, Sørensen B, et al. (2014) Comparable Cellular Immune Responses in Patients with and without Antiretroviral Treatment after Immunization with HIV-1 P24, P17 and Tat Consensus Peptides (Vacc-5q). J AIDS Clin Res 5: 296. doi:10.4172/2155-6113.1000296

period of 9 months, with 10 subjects in each ART study arm. Two patients in the non-ART-group did not complete the study; one died after week 3 (see below) and one was lost to follow-up after week 28 . All patients in the ART-group were effectively controlled at enrolment, having HIV RNA $<50$ copies $/ \mathrm{ml}$ and CD4+ T cell counts 535 cells $/ \mu$ l. The non-ART group had similar CD4 count levels as the ART-group but otherwise typical characteristics of chronic HIV-infected patients in early phase with significantly higher CD8+ T cell counts and signs of persistent immune activation such as elevated CD38+CD8+ T cells levels of $\beta_{2}$-microglobulin and IgG, and higher numbers of CD28CD8+ effector T cells. The baseline characteristics are outlined in Table 1. The longitudinal development of CD4 counts and HIV RNA levels for each study arm is presented in Figure 2, showing transient viremia in the ART-group at week 40 after 12 weeks of treatment interruption per protocol. In the non-ART group, a small but significant $(\mathrm{p}=0.05)$ increase in their viral loads was observed from week 0-24 (Figure 2) that was no longer present at week 40 .

At follow-up week 185, 14 patients (74\%) were recruited 3.5 years (median) after the primary inclusion date; 7 subjects from each study arm of whom 9 volunteered for a final Vacc-5q DTH. All participants were still without any HIV-related symptoms with similar CD4 count levels in the ART and non-ART study arms (CD4 350 (310-460) and $450(240-480)$ cells $/ \mu$ l, respectively) (Figure 2 ). All patients from the non-ART-group were still without treatment, and all but one patient in the ART-group had restarted ART after the last treatment interruption.

\section{Safety}

Nine patients (4 from the non-ART- and 5 from the ART-group)
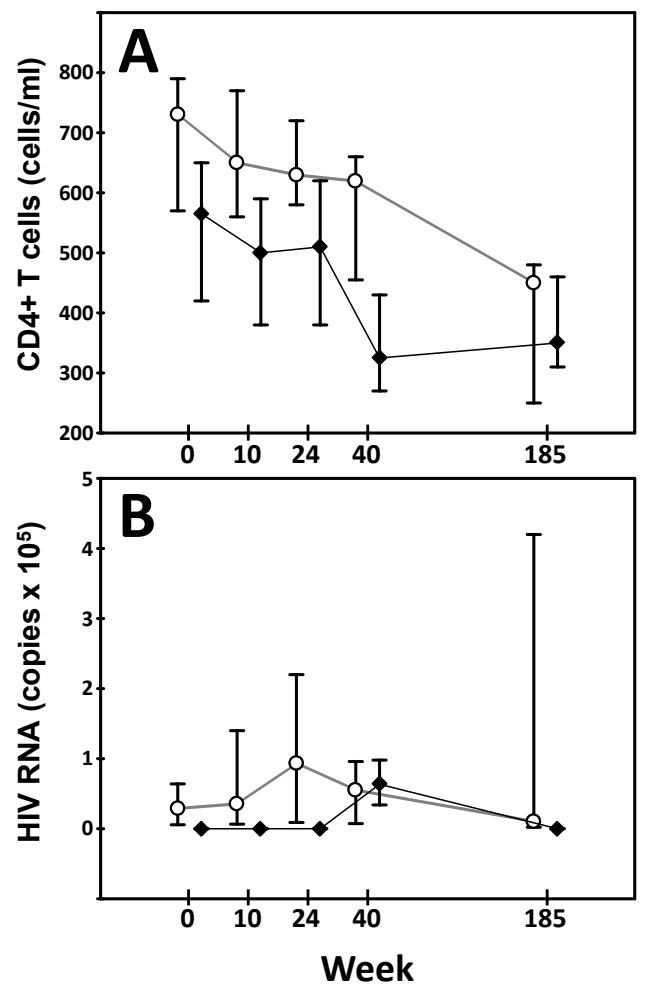

Figure 2: Time-dependent changes in a) CD4+ T cell counts and b) HIV RNA within the study arms for non-ART (open markers, dashed line) and ART patients (black markers, solid line). Medians and interquartile ranges are indicated.

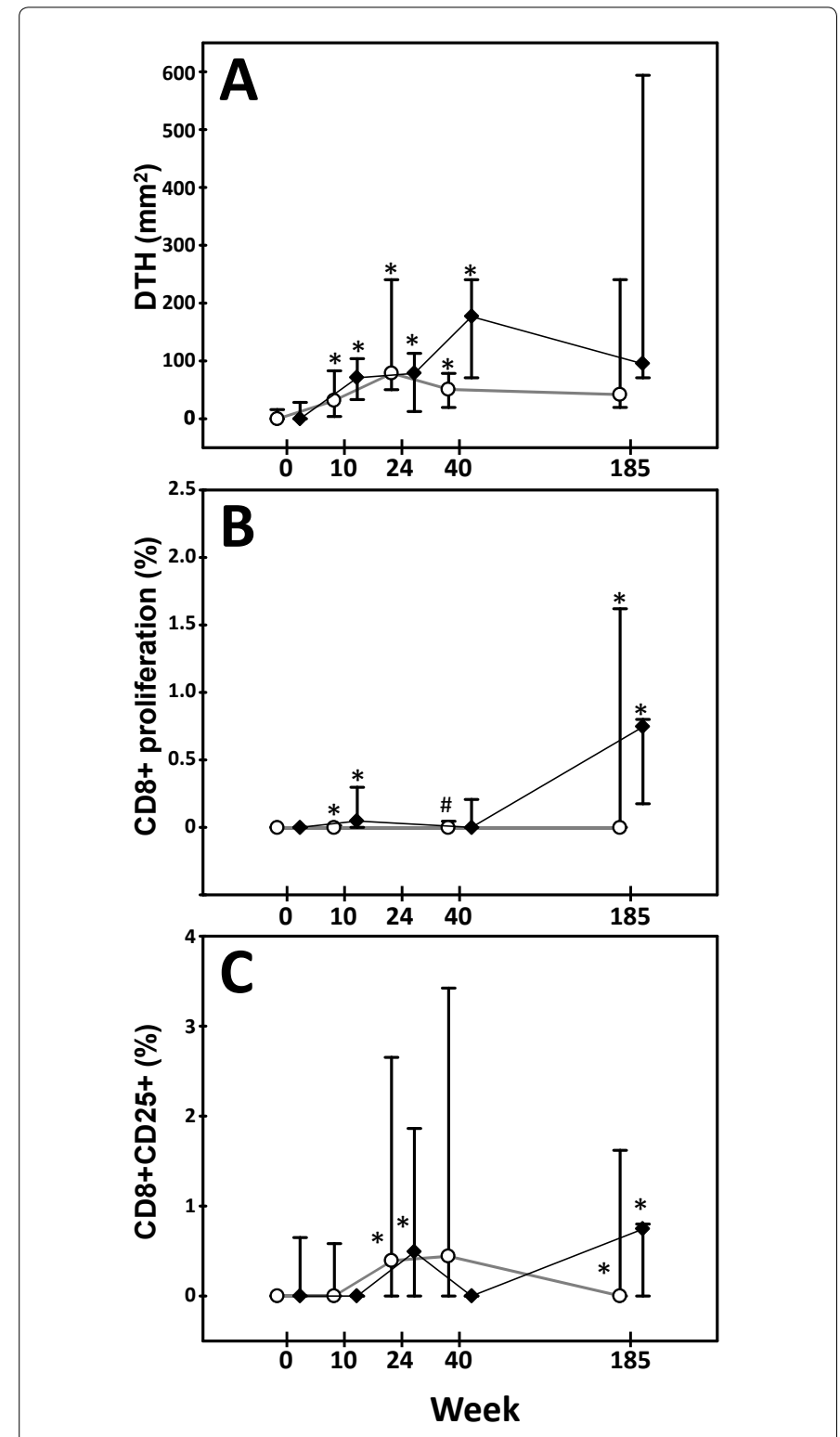

Figure 3: Longitudinal changes in response parameters following immunization. Results shown for patients in the non-ART group (open markers, dashed line) and ART group (black markers, solid line) at selected time-points.

a) Vacc-5q DTH skin induration areas. The size was significantly increased from baseline in both study arms at weeks 10, 24, and 40 (marked with *), and weeks 4 and 28 (not shown). There were no significant differences between the study arms.

b) Proliferative $C D 8+T$ cell responses to Vacc- $5 q$ peptides. The responses were significantly increased from baseline in both study arms at weeks 10 and 185 (marked with *), and in the non-ART group at week 24 (marked with \#). There were no significant differences between the two study arms.

c) CD8+ T cell activation in terms of CD25 expression. The responses were significantly increased from baseline in both study arms at weeks 24, and 185 (marked with *), and at week 4 (not shown).

reported mild, transient influenza-like symptoms or tiredness on the vaccination day (graded as mild). One patient on ART experienced two episodes of transient systemic allergic reactions at week 26 and in connection with DTH skin test at week 28 , where after he did not received further DTH tests. The reaction was characterized by skin flushing and presyncope lasting for a few seconds, and was graded as moderate. A few episodes of transient mild infections were observed 
Citation: Kran AMB, Lind A, Sommerfelt MM, Baksaas I, Sørensen B, et al. (2014) Comparable Cellular Immune Responses in Patients with and without Antiretroviral Treatment after Immunization with HIV-1 P24, P17 and Tat Consensus Peptides (Vacc-5q). J AIDS Clin Res 5: 296. doi:10.4172/2155-6113.1000296

Page 5 of 8

during the immunization period, and were considered to have no or uncertain relation to Vacc-5q. The infections were herpes zoster (graded as moderate), and an outbreak of genital herpes simplex infection (graded as mild).

In the non-ART-group, one patient was found dead at home 3 weeks after inclusion. A certain cause of death was impossible to establish due to the considerable decay of the corpse. However, the forensic evaluation favoured intoxication in relation to drug abuse as cause of death, based on the high levels of alprazolam, codeine and ethanol found in the deceased.

\section{Vacc-5q responses in vivo (DTH)}

At baseline, ten patients (5 in each study arm) had weakly positive DTH tests above $10 \mathrm{~mm}^{2}$, with similar induration area in the ART (0 $\left.\mathrm{mm}^{2}(0-28)\right)$ and the non-ART $\left(0 \mathrm{~mm}^{2}(0-16)\right)$ groups. There was a significant increase in DTH induration size from baseline to all time points $(p<0.001)$ (Figure 3$)$. Considering both groups together, DTH was still markedly positive and higher than baseline at follow-up week 185 (71 mm2 (33-241), $\mathrm{p}=0.008)$ and similar to DTH obtained at weeks 10 (first ART stop), 28 (second ART stop), and 40 (end of study).

Overall, Vacc-5q DTH responses improved in $16(84 \%)$ of the 19 eligible patients during the study with no significant differences between the study arms (90\% and $78 \%$ of the patients at end-of-study in the ART- and non-ART-group, respectively) (Table 2).

\section{$\mathrm{T}$ cell responses in vitro}

At baseline, median proliferative responses to Vacc-5q were similarly undetectable in both treatment arms, and only three patients had weak detectable responses. The overall proliferative $\mathrm{T}$ cell-response rates relative to baseline were $59 \%$ after the first immunization period at week 10 and $58 \%$ after the second boosting period at week 40 (Table 2). In quantitative terms, Vacc-5q-specific proliferative responses at week 10 transiently increased from baseline for both the CD4+ $(\mathrm{p}<0.01)$ and the CD8+ $(\mathrm{p}=0.05)$ subsets (Figure 3$)$. No significant differences were found between the study arms at week 10, but proliferative CD4+ responses increased more explicitly from baseline for patients on ART $(p=0.04)$ than for non-ART patients $(p=0.07)$. After completed immunizations at week 40 , all patients had viremia due to interruption of ART from week 28. The CD8+ T cell responses to Vacc-5q still tended to be higher than baseline ( $\mathrm{p}=0.08$ ) with no differences between the two study arms (Figure $3 \mathrm{~b}$ ). These CD8+ T cell responses remained higher than baseline even three years later at week $185(\mathrm{p}=0.03)$, still with no differences between the study subgroups (data not shown).

Enhanced expression of CD25 in responses to vaccine antigens was used as an alternative parameter for $\mathrm{CD} 8+\mathrm{T}$ cell activation at more time points. CD25 is the $\alpha$-chain of the high affinity IL-2 receptor, and in long-term cultures, enhanced expression of CD25 depicts the most newly proliferated cell population and not all proliferated cells [22]. Vacc-5q-specific responses in terms of increased expression of CD25 relative to baseline, were generally in keeping with the proliferative responses described above.

Using Vacc-5q induced changes in CD25 fractions relative to baseline, $\mathrm{CD} 8+\mathrm{T}$ cell responses increased already at end of the primary immunization period week $4(\mathrm{p}<0.01)$ and in fact more so in the nonART compared with the ART group ( $\mathrm{p}=0.02)$. These $\mathrm{CD} 8+$ responses were still significantly and similarly enhanced in both study arms before booster vaccination at week $24(\mathrm{p}=0.01)$ as shown in Figure $3 c$. Even at week 185 the Vacc-5q responses were still significantly higher than

\begin{tabular}{|c|c|c|c|c|c|c|c|c|}
\hline \multirow{2}{*}{ Antigen } & \multirow{2}{*}{ Assay } & \multirow{2}{*}{$\mathrm{T}$ cell subset } & \multicolumn{3}{|c|}{ Week $10^{*}$} & \multicolumn{3}{|c|}{ Week 40} \\
\hline & & & All & $A R T-$ & $A R T+$ & All & ART- & ART+ \\
\hline \multirow{7}{*}{ Vacc-5q } & DTH high & n.a. & $76 \%$ & $63 \%(8)^{\star *}$ & $89 \%(9)$ & $84 \%$ & $78 \%(9)$ & $90 \%(10)$ \\
\hline & DTH low & n.a. & $67 \%$ & $63 \%(8)$ & $80 \%(10)$ & $74 \%$ & $67 \%(9)$ & $80 \%(10)$ \\
\hline & \multirow{2}{*}{ Proliferation } & CD4 & $59 \%$ & $50 \%(8)$ & $67 \%(9)$ & $58 \%$ & $44 \%(9)$ & $70 \%(10)$ \\
\hline & & CD8 & $35 \%$ & $25 \%(8)$ & $44 \%(9)$ & $42 \%$ & $22 \%(9)$ & $60 \%(10)$ \\
\hline & CD25 & CD8 & $21 \%$ & $29 \%(7)$ & $14 \%(7)$ & $31 \%$ & $44 \%(9)$ & $20 \%(10)$ \\
\hline & \multirow{2}{*}{$\mathrm{IFN}-\gamma^{+}$} & CD4 & $8 \%$ & $0 \%(6)$ & $22 \%(9)$ & $30 \%$ & $29 \%(7)$ & $30 \%(10)$ \\
\hline & & CD8 & $33 \%$ & $33 \%(6)$ & $33 \%(9)$ & $47 \%$ & $29 \%(7)$ & $60 \%(10)$ \\
\hline \multirow{2}{*}{ Nat-5q $q^{\star \star *}$} & Proliferation & CD8 & $24 \%$ & $38 \%(8)$ & $11 \%(9)$ & $33 \%$ & $33 \%(9)$ & $33 \%(9)$ \\
\hline & CD25 & CD8 & $38 \%$ & $67 \%(6)$ & $14 \%(7)$ & $33 \%$ & $44 \%(9)$ & $22 \%(9)$ \\
\hline \multirow{2}{*}{ p17 protein } & Proliferation & CD8 & $19 \%$ & $29 \%(7)$ & $11 \%(9)$ & $24 \%$ & $29 \%(7)$ & $20 \%(10)$ \\
\hline & CD25 & CD8 & $0 \%$ & $0 \%(5)$ & $14 \%(7)$ & $50 \%$ & $56 \%(9)$ & $44 \%(9)$ \\
\hline \multirow{2}{*}{ p24 protein } & Proliferation & CD8 & $38 \%$ & $57 \%(7)$ & $22 \%(9)$ & $69 \%$ & $71 \%(7)$ & $67 \%(9)$ \\
\hline & CD25 & CD8 & $33 \%$ & $40 \%(5)$ & $29 \%(7)$ & $61 \%$ & $78 \%(9)$ & $44 \%(9)$ \\
\hline \multirow{2}{*}{ Tat protein } & Proliferation & CD8 & $0 \%$ & $0 \%(7)$ & $0 \%(9)$ & $19 \%$ & $14 \%(7)$ & $22 \%(9)$ \\
\hline & CD25 & CD8 & $18 \%$ & $25 \%(4)$ & $14 \%(7)$ & $34 \%$ & $56 \%(9)$ & $11 \%(9)$ \\
\hline
\end{tabular}

*No differences between the ART- and ART+ groups (Fisher exact test)

${ }^{* *}$ Frequency of responses relative to baseline (total $n$ )

${ }^{* * *}$ Nat- $5 q$ are the native, unmodified peptides corresponding to the vaccine.

Table 2: Responses to various antigens relative to baseline.

\begin{tabular}{|c|c|c|}
\hline Vacc-5q peptide & Corresponding peptide & Corresponding strain sequence in HXB2 reference \\
\hline 1 & P24 (Vacc-13) & KALGPAATLEEMMTACQGVG \\
\hline 2 & P24 & GATPQDLNTMLNTVGGHQAA \\
\hline 3 & P17 & HIVWASRELERFAVNPGLEVT \\
\hline 4 & Tat & SVDPRLEPWKHPGSQPKTACTN \\
\hline 5 & Tat & QVCFITKGLGISYGRKK \\
\hline
\end{tabular}

Table 3. The native sequences used as basis for peptide design. 
Citation: Kran AMB, Lind A, Sommerfelt MM, Baksaas I, Sørensen B, et al. (2014) Comparable Cellular Immune Responses in Patients with and without Antiretroviral Treatment after Immunization with HIV-1 P24, P17 and Tat Consensus Peptides (Vacc-5q). J AIDS Clin Res 5: 296. doi:10.4172/2155-6113.1000296

baseline and for both $\mathrm{T}$ cell subsets $(\mathrm{p}<0.05)$, again without differences between the original ART and non-ART groups (data not shown).

Cross reactivity between the Vacc-5q peptides and recombinant p24, p17 and Tat whole proteins were also tested. The CD4+ T cellresponses to recombinant $\mathrm{p} 24, \mathrm{p} 17$ and Tat were generally weak but detectable at baseline in the ART-group and highest against p24. The $\mathrm{CD} 8+\mathrm{T}$ cell-responses to all three proteins increased from baseline both after the primary immunization at week $4(\mathrm{p}=<0.01)$ and before the boost period at week $24(\mathrm{p}=<0.04)$, but only the p24 and $\mathrm{p} 17$ specific responses persisted at end of study at week $40(\mathrm{p}<0.03)$. No differences between ART and non-ART patients in these enhanced CD8+ responses were detected at any time point. The frequencies of responses to the various antigens are shown in Table 2.

\section{Discussion}

Here we present data from an early phase I/II trial showing that intradermal administration of Vacc-5q peptides using GM-CSF as local adjuvant, safely resulted in sustained $\mathrm{T}$ cell responses according to both in vivo (DTH) and in vitro assays. We found that Vacc-5q peptides enhanced responses to the corresponding recombinant proteins, and an overall response rate at $84 \%$. We have previously found similar, longlasting responses after immunization with another therapeutic vaccine candidate (Vacc- $4 \mathrm{x}$ ) consisting of four HIV p24 consensus peptides which were identically administered $[4,17,18,20]$, and recently shown to improve viral control [10]. Taken together, these trials confirm the potential for this procedure [26]. While Vacc-4x consists only of p24like peptides, Vacc-5q includes additional peptides derived from $\mathrm{p} 17$ and Tat sequences. Using p 24 as an antigen is justified by early studies showing that sustained cellular immune responses to p24 are associated with a favorable clinical development [27-29]. Matrix-protein p17 were included as it represents a conserved domain where immune escape may come at a fitness cost. Moreover, peptides derived from Tat were included because Tat is associated with many pathogenic effects, described to substantiate it as a vaccine target [30], although later clinical trials focusing on Tat alone have not shown effect [3133]. Finally, local low dose GM-CSF was used as an adjuvant prior to vaccination, similar to Vacc- $4 \mathrm{x}$ and in peptide-based cancer vaccines [34-36].

The current trial shows the ability of the Vacc- $5 \mathrm{q}$ peptides to elicit potent HIV-associated cellular immune responses not only in chronic HIV-patients stable on ART, but also in treatment-naïve patients with sustained viremia. Most patients in both study arms enhanced robust cellular immune responses both in vivo by DTH, and in vitro with overall similar response rates in the two groups. To our knowledge, this is one of the first trials to directly compare the immunization potential between patients on stable ART and ART-naïve progressing patients. In most clinical therapeutic vaccine trials, the strategy has been to boost immunity to HIV while the virus is fully suppressed by ART, with only few exceptions [9,16,37-39]. This approach has been based on the theoretical notion that effective ART provides the best condition for immunisation by reducing HIV-infection of vaccine-activated CD4+ T cells.

We here included patients without ART primarily for safety reasons, and did not design a formal study of inferiority or clinical efficacy. Two challenges are evident in such a comparison. First, although the current CD4 counts were similar in both study arms and the non-ART patients had a typical progressor phenotype, the history of chronic HIV infection was quite different. In particular, the ART group had a nadir CD4 count of 190 cells/ $\mu$ l. Although we know from our previous experience with Vacc- $4 \mathrm{x}$ (4) that such patients can later be effectively immunized, lower nadir CD4 counts may hamper the responsiveness to immunization [40,41]. Secondly, although Vacc-5q induced comparable HIV-associated cellular immune responses in both study arms in terms of response rates, strength and long-term duration, this safety trial included only 20 patients. Thus, the statistical power is too weak to clearly discriminate the groups. However, our hypothesis was that the ART-free study group would be difficult to iimmunize to such an extent that it would have been revealed even with this sample size. A final notion was that a transient increase in viral load was observed in the ART naive group This could be due to activation of HIV-1 CD4+ T cell targets by either Vacc- $5 \mathrm{q}$ or by GM-CSF, however, the increase was brief and transient, and might also be explained by assay variation or the low number of study subjects.

In contrast to the assumption that ART is necessary for effective immunization, we found that Vacc-5q induced comparable HIVassociated cellular immune responses in both study arms in terms of response rates, strength, long-term duration and safety. There is a global trend towards initiating ART earlier. Some recent recommendations even include offering ART to all patients regardless of CD4 cell count levels [42]. However, access to ART for all HIV infected individuals is unfortunately still not a realistic option. A therapeutic vaccine that is effective in untreated individuals and could delay the decline in CD4 cells and help maintain low viral loads, would have an important impact especially for patients in areas with limited access to ART. In the current study, no antiviral effect of Vacc-5q was demonstrated, but this small phase-I study was not designed to study efficacy. Our data should therefore encourage new trials comparing early immunization at high CD4 counts with and without concurrent ART.

Due to the extensive genetic variation of HIV, HIV-specific immune responses targeting particular epitopes may not be equally relevant for all viral variants. Although the vaccine was not adapted to the subjects' individual HLA types, a mapping of epitopes corresponding to HLAtype for each patient could have clarified specific epitopes in greater detail. Furthermore, determination of the subject's HIV-1 amino acid sequence in the five areas targeted by Vacc-5q, would also enable studies of immune escape and possible vaccine-induced amino acid sequence changes. However, these data were not attainable in this small explorative phase I study, but should be considered in further studies.

Among the shortcomings of the present study, are the lack of updated functional $\mathrm{T}$ cell-assays such as measures of antiviral activity, and polyfunctional $\mathrm{T}$ cell markers, as the study was initiated many years ago. Development of peptide-specific antibodies was not characterized since the procedure mainly generates cellular immune responses, in keeping with our experience with Vacc-4x. Although this makes a direct comparison of the results with other studies difficult, specific T cell proliferation is still considered to reflect beneficial HIVrelated responses, and the methods applied therefore seem sufficient to demonstrate that specific $\mathrm{T}$ cell responses were in fact induced by the vaccine. Robust proliferative responses were chosen as a key parameter, as this response modality has been firmly linked to improved control of the infection [43]. In contrast, although DTH may provide a simple read-out in clinical practice, it has been little explored and validated in this field. Moreover, we have previously demonstrated that DTH is a more stable and possibly more reliable parameter for $\mathrm{T}$ cell responses and presence of HIV-specific clones during viremia, where such T cells may be nearly lost in blood but still reside in lymphoid tissues [44]. It is therefore noteworthy that the overall response rates for DTH appeared better than for the corresponding in vitro assays, particularly at week 40 
Citation: Kran AMB, Lind A, Sommerfelt MM, Baksaas I, Sørensen B, et al. (2014) Comparable Cellular Immune Responses in Patients with and without Antiretroviral Treatment after Immunization with HIV-1 P24, P17 and Tat Consensus Peptides (Vacc-5q). J AIDS Clin Res 5: 296. doi:10.4172/2155-6113.1000296

where all patients were viremic (Table 2). Thus, one can speculate that DTH may be the most stable longitudinal comparator between viremic and aviremic patients. With this parameter, the patients on ART seemed to have overall higher response rates, although not significantly so. However, proliferative data support this notion, showing more distinct changes from baseline and better preservation of CD8+ T cell responses in the ART group even during viremia at end of study week 40. Nevertheless, even $60-80 \%$ of the ART-naïve individuals responded to immunization with HIV consensus peptides.

Therapeutic HIV vaccines have recently been suggested as a potentially essential part of HIV cure regimen, since the prime immune deficiency in healthy HIV-infected individuals is immunity to HIV $[3,45,46]$. This potential niche should therefore encourage intensified efforts in vaccine development. It should be emphasized that a number of antigens and delivery systems have been and is currently tested as therapeutic vaccines $[10,33,47-50]$.

In conclusion, our data show that strong, specific, and early cellular immune responses against Vacc-5q, in both patients stable on ART and treatment-naïve patients having similar $\mathrm{CD} 4+\mathrm{T}$ cell-counts. Furthermore, T cell-responses both in vivo and in vitro were maintained even 3.5 years after immunization, independent of the presence of ART during immunizations. Prospective studies are required to determine the clinical relevance of these responses, and whether peptide-based therapeutic immunizations could postpone the initiation of ART.

\section{Acknowledgements}

This study was supported by the Research council of Norway in the GLOBVAC program, grant \#192514. We particularly thank all participants and the invaluable technical assistance from Mette Sannes and Malin Jørgensen.

\section{References}

1. Moir S, Chun TW, Fauci AS (2011) Pathogenic mechanisms of HIV disease Annu Rev Pathol 6: 223-248.

2. McDermott $A B$, Koup RA (2012) CD8(+) T cells in preventing HIV infection and disease. AIDS 26: 1281-1292.

3. Katlama C, Deeks SG, Autran B, Martinez-Picado J, van Lunzen J, et al. (2013) Barriers to a cure for HIV: new ways to target and eradicate HIV-1 reservoirs. Lancet 381: 2109-2117.

4. Kran AM, Sørensen B, Nyhus J, Sommerfelt MA, Baksaas I, et al. (2004) HLAand dose-dependent immunogenicity of a peptide-based HIV-1 immunotherapy candidate (Vacc-4x). AIDS 18: 1875-1883.

5. Harari A, Rozot V, Cavassini M, Enders FB, Vigano S, et al. (2012) NYVAC immunization induces polyfunctional HIV-specific T-cell responses in chronically-infected, ART-treated HIV patients. Eur J Immunol 42: 3038-3048.

6. Dorrell L, Yang H, Ondondo B, Dong T, di GK, et al. (2006) Expansion and diversification of virus-specific $T$ cells following immunization of human immunodeficiency virus type 1 (HIV-1)-infected individuals with a recombinant modified vaccinia virus Ankara/HIV-1 Gag vaccine. J Virol 80: 4705-4716.

7. Harari A, Bart PA, Stöhr W, Tapia G, Garcia M, et al. (2008) An HIV-1 clade C DNA prime, NYVAC boost vaccine regimen induces reliable, polyfunctional, and long-lasting T cell responses. J Exp Med 205: 63-77.

8. Lisziewicz J, Bakare N, Calarota SA, Bánhegyi D, Szlávik J, et al. (2012) Single DermaVir immunization: dose-dependent expansion of precursor/memory T cells against all HIV antigens in HIV-1 infected individuals. PLoS One 7: e35416.

9. García F, Climent N, Assoumou L, Gil C, González N, et al. (2011) A therapeutic dendritic cell-based vaccine for HIV-1 infection. J Infect Dis 203: 473-478.

10. Pollard RB, Rockstroh JrK, Pantaleo G, Asmuth DM, Peters B, et al. (2014) Safety and efficacy of the peptide-based therapeutic vaccine for HIV-1, Vacc$4 \mathrm{x}$ : a phase 2 randomised, double-blind, placebo-controlled trial. Lancet Infect Dis 14: 291-300.

11. Kloverpris H, Karlsson I, Bonde J, Thorn M, Vinner L, et al. (2009) Induction of novel CD8+ T-cell responses during chronic untreated HIV-1 infection by immunization with subdominant cytotoxic T-lymphocyte epitopes. AIDS 23: 1329-1340.

12. Borthwick N, Ahmed T1, Ondondo B2, Hayes P3, Rose A4, et al. (2014) Vaccine-elicited human $T$ cells recognizing conserved protein regions inhibit HIV-1. Mol Ther 22: 464-475.

13. Leroux-Roels G, Maes C, Clement F, van Engelenburg F, van den Dobbelsteen M, et al. (2013) Randomized Phase I: Safety, Immunogenicity and Mucosa Antiviral Activity in Young Healthy Women Vaccinated with HIV-1 Gp41 P1 Peptide on Virosomes. PLoS One 8: e55438.

14. Karlsson I, Brandt L, Vinner L, Kromann I, Andreasen LV, et al. (2013) Adjuvanted HLA-supertype restricted subdominant peptides induce new T-cell immunity during untreated HIV-1-infection. Clin Immunol 146: 120-130.

15. Boffito M, Fox J, Bowman C, Fisher M, Orkin C, et al. (2013) Safety, immunogenicity and efficacy assessment of HIV immunotherapy in a multicentre, double-blind, randomised, Placebo-controlled Phase lb human trial Vaccine 31: 5680-5686.

16. Harrer T, Plettenberg A2, Arastéh K3, Van Lunzen J4, Fätkenheuer G5, et al (2013) Safety and immunogenicity of an adjuvanted protein therapeutic HIV1 vaccine in subjects with HIV-1 infection: A randomised placebo-controlled study. Vaccine.

17. Kran AM, Sommerfelt MA, Sørensen B, Nyhus J, Baksaas I, et al. (2005) Reduced viral burden amongst high responder patients following HIV-1 p24 peptide-based therapeutic immunization. Vaccine 23: 4011-4015.

18. Kran AM, Sørensen B, Sommerfelt MA, Nyhus J, Baksaas I, et al. (2006) Longterm HIV-specific responses and delayed resumption of antiretroviral therapy after peptide immunization targeting dendritic cells. AIDS 20: 627-630.

19. Asjö B, Stavang H, Sørensen B, Baksaas I, Nyhus J, et al. (2002) Phase I tria of a therapeutic HIV type 1 vaccine, Vacc-4x, in HIV type 1-infected individuals with or without antiretroviral therapy. AIDS Res Hum Retroviruses 18: 13571365.

20. Kran AM, Sommerfelt MA, Baksaas I, Sørensen B, Kvale D (2012) Delayedtype hypersensitivity responses to HIV Gag p24 relate to clinical outcome after peptide-based therapeutic immunization for chronic HIV infection. APMIS 120: 204-209.

21. Pettersen FO, Taskén K, Kvale D (2010) Combined Env- and Gag-specific T cell responses in relation to programmed death-1 receptor and CD4 T cell loss rates in human immunodeficiency virus-1 infection. Clin Exp Immunol 161: 315323.

22. Fazekas de St Groth B, Smith AL, Higgins CA (2004) T cell activation: in vivo veritas. Immunol Cell Biol 82: 260-268.

23. Lind A, Brekke K, Pettersen FO, Mollnes TE, Trøseid M, et al. (2014) A parameter for IL-10 and TGF- $B$ mediated regulation of HIV-1 specific T cel activation provides novel information and relates to progression markers. PLoS One 9: e85604.

24. Nyhus J, Kran AM, Sommerfelt MA, Baksaas I, Sorensen B, et al. (2006) Multiple antigen concentrations in delayed-type hypersensitivity (DTH) and response diversity during and after immunization with a peptide-based HIV-1 immunotherapy candidate (Vacc-4x). Vaccine. 24: 1543-1550.

25. BD B (2000) Detecting Cytokines in Antigen-Activated Lymphocytes.

26. Sommerfelt MA, Sørensen B (2008) Prospects for HIV-1 therapeutic immunisation and vaccination: the potential contribution of peptide immunogens. Expert Opin Biol Ther 8: 745-757.

27. Kiepiela P, Ngumbela K, Thobakgale C, Ramduth D, Honeyborne I, et al. (2007) CD8+ T-cell responses to different HIV proteins have discordant associations with viral load. Nat Med 13: 46-53.

28. Zuñiga R, Lucchetti A, Galvan P, Sanchez S, Sanchez C, et al. (2006) Relative dominance of Gag p24-specific cytotoxic T lymphocytes is associated with human immunodeficiency virus control. J Virol 80: 3122-3125.

29. Rolland M, Heckerman D, Deng W, Rousseau CM, Coovadia H, et al. (2008) Broad and Gag-biased HIV-1 epitope repertoires are associated with lower viral loads. PLoS One 3: e1424.

30. Goldstein G, Damiano E, Donikyan M, Pasha M, Beckwith E, et al. (2012) HIV-1 Tat B-cell epitope vaccination was ineffectual in preventing viral rebound after ART cessation: HIV rebound with current ART appears to be due to infection 
Citation: Kran AMB, Lind A, Sommerfelt MM, Baksaas I, Sørensen B, et al. (2014) Comparable Cellular Immune Responses in Patients with and without Antiretroviral Treatment after Immunization with HIV-1 P24, P17 and Tat Consensus Peptides (Vacc-5q). J AIDS Clin Res 5: 296. doi:10.4172/2155-6113.1000296

Page 8 of 8

with new endogenous founder virus and not to resurgence of pre-existing Tatdependent viremia. Hum Vaccin Immunother 8: 1425-1430.

31. Longo O, Tripiciano A, Fiorelli V, Bellino S, Scoglio A, et al. (2009) Phase I therapeutic trial of the HIV-1 Tat protein and long term follow-up. Vaccine 27 : 3306-3312.

32. Ensoli B, Fiorelli V, Ensoli F, Lazzarin A, Visintini R, et al. (2009) The preventive phase I trial with the HIV-1 Tat-based vaccine. Vaccine 28: 371-378.

33. Ensoli B, Bellino S, Tripiciano A, Longo O, Francavilla V, et al. (2010) Therapeutic immunization with HIV-1 Tat reduces immune activation and loss of regulatory T-cells and improves immune function in subjects on HAART. PLoS One 5: e13540.

34. Hunger RE, Brand CU, Streit M, Eriksen JA, Gjertsen MK, et al. (2001) Successful induction of immune responses against mutant ras in melanoma patients using intradermal injection of peptides and GM-CSF as adjuvant. Exp Dermatol 10: 161-167.

35. Disis ML, Bernhard H, Shiota FM, Hand SL, Gralow JR, et al. (1996) Granulocyte-macrophage colony-stimulating factor: an effective adjuvant for protein and peptide-based vaccines. Blood 88: 202-210.

36. Gjertsen MK, Buanes T, Rosseland AR, Bakka A, Gladhaug I, et al. (2001) Intradermal ras peptide vaccination with granulocyte-macrophage colonystimulating factor as adjuvant: Clinical and immunological responses in patients with pancreatic adenocarcinoma. Int J Cancer 92: 441-450.

37. Lu W, Arraes LC, Ferreira WT, Andrieu JM (2004) Therapeutic dendritic-cell vaccine for chronic HIV-1 infection. Nat Med 10: 1359-1365

38. Goldstein G, Chicca JJ (2012) Exploratory clinical studies of a synthetic HIV1 Tat epitope vaccine in asymptomatic treatment-naive and antiretroviralcontrolled HIV-1 infected subjects plus healthy uninfected subjects. Hum Vaccin Immunother 8: 479-485.

39. Vardas E, Stanescu I, Leinonen M, Ellefsen K, Pantaleo G, et al. (2012) Indicators of therapeutic effect in FIT-06, a Phase II trial of a DNA vaccine, GTU(®)-Multi-HIVB, in untreated HIV-1 infected subjects. Vaccine 30: 40464054.

40. Gudmundsdotter L, Wahren B, Haller BK, Boberg A, Edbäck U, et al. (2011) Amplified antigen-specific immune responses in HIV-1 infected individuals in a double blind DNA immunization and therapy interruption trial. Vaccine 29 : 5558-5566.

41. Leon A, Martinez E, Milinkovic A, Mora B, Mallolas J, et al. (2009) Influence of repeated cycles of structured therapy interruption on the rate of recovery of CD4+ $T$ cells after highly active antiretroviral therapy resumption. J Antimicrob Chemother 63:184-188.

42. Thompson MA, Aberg JA, Hoy JF, Telenti A, Benson C, et al. (2012) Antiretrovira treatment of adult HIV infection: 2012 recommendations of the International Antiviral Society-USA panel. JAMA 308: 387-402.

43. Lieberman J, Shankar P, Manjunath N, Andersson J (2001) Dressed to kill? A review of why antiviral CD8 $T$ lymphocytes fail to prevent progressive immunodeficiency in HIV-1 infection. Blood 98: 1667-1677.

44. Kvale D, Kran AM, Sommerfelt MA, Nyhus J, Baksaas I, et al. (2005) Divergent in vitro and in vivo correlates of HIV-specific T-cell responses during onset of HIV viraemia. AIDS 19: 563-567.

45. García F, León A, Gatell JM, Plana M, Gallart T (2012) Therapeutic vaccines against HIV infection. Hum Vaccin Immunother 8: 569-581.

46. Deeks SG, Autran B, Berkhout B, Benkirane M, Cairns S, et al. (2012) Towards an HIV cure: a global scientific strategy. Nature reviews Immunology 12: 607614

47. Lisziewicz J, Trocio J, Xu J, Whitman L, Ryder A, et al. (2005) Control of viral rebound through therapeutic immunization with DermaVir. AIDS 19: 35-43.

48. Schooley RT, Spritzler J, Wang H, Lederman MM, Havlir D, et al. (2010) AIDS clinical trials group 5197: a placebo-controlled trial of immunization of HIV-1-infected persons with a replication-deficient adenovirus type 5 vaccine expressing the HIV-1 core protein. J Infect Dis 202: 705-716.

49. Rerks-Ngarm S, Paris RM, Chunsutthiwat S, Premsri N, Namwat C, et al. (2013) Extended evaluation of the virologic, immunologic, and clinical course of volunteers who acquired HIV-1 infection in a phase III vaccine trial of ALVACHIV and AIDSVAX B/E. J Infect Dis 207: 1195-1205.

50. García F, Climent N, Guardo AC, Gil C, León A, et al. (2013) A dendritic cell-based vaccine elicits $T$ cell responses associated with control of HIV-1 replication. Sci Transl Med 5: 166ra2. 